\title{
SOME PROBLEMS OF CONTROLLING THE CABLE PROPULSION DEVICES OF MOBILE ROBOTS
}

\author{
E. S. BRISKIN and N. G. SHARONOV \\ Department of Theoretical Mechanics, Volgograd State Technical University, \\ Lenin av., 28, Volgograd, 400005, Russia \\ Center for Technology Components of Robotics and Mechatronics, Innopolis University, \\ Universitetskaya str., 1, Innopolis, 420500, Russia \\ E-mail:sharonov@vstu.ru \\ dtm.vstu.ru
}

M. I. EFIMOV, V. V. GULEVSKY and I. S. PENSHIN

Department of Theoretical Mechanics, Volgograd State Technical University, Lenin av., 28, Volgograd, 400005, Russia

E-mail:dtm@vstu.ru

dtm.vstu.ru

\begin{abstract}
Some tasks of mobile robots motion control with "clinging" propulsion devices that work only in the "pullup" mode to a fixed support are considered, which is due to the flexibility of the cables used in propulsors. A method of moving by means of "clinging" anchor-cable propulsion devices attached to an underwater platform with a small positive buoyancy is described. The principle of the operation of robots of vertical motion with cable drives and the problems of calculating their modes of motion are described. Methods for solving the problem of mobile robots motion control with "clinging" propulsion devices with excessive nonstationary connections are given.
\end{abstract}

\section{Introduction}

Mobile robots having wheeled, tracked, walking and crawling movers [1-6], the traction properties of which are due to the force of interaction with the supporting surface due to the weight of the robot are known. However, other types of robots are known for which the forces of interaction with the supporting surface are independent of its weight. What robots include, for example, robots moving along vertical surfaces due to the aerodynamic or hydrodynamic pressing of the propulsion devices supports to the surface, the use of vacuum suction cups, electromagnetic forces of interaction with the supporting surface, etc. [7-10]. Propulsion devices are also known that reliably interact with a supporting surface, usually close to a cylindrical shape, due to its "force girth" [11-13].

To propulsion devices, not leaning on the supporting surface, but clinging to it, include cable propulsion devices [14-15]. Their feature is the ability to implement only the "pulling" effect on the robot from external bodies. The robot does not lean on them, but can only be pulled towards them. Such propulsion devices can be used to move underwater pontoons with a payload, and they can be classified as anchor-cable propulsion devices [16, 17]. Cable propulsion devices can be used both for movement and on vertical surfaces [18] with reliable fixation on it.

Each of the propulsion devices has its own characteristics that require accounting and research. Some of them are considered in the presented work. 


\section{The principle of operation of anchor-cable propulsors and the problems of calculating their modes of movement}

The method of moving technological equipment in the near-bottom zone by means of anchorcable propulsion devices attached to the platform with a small positive buoyancy is shown schematically in Figure 1.

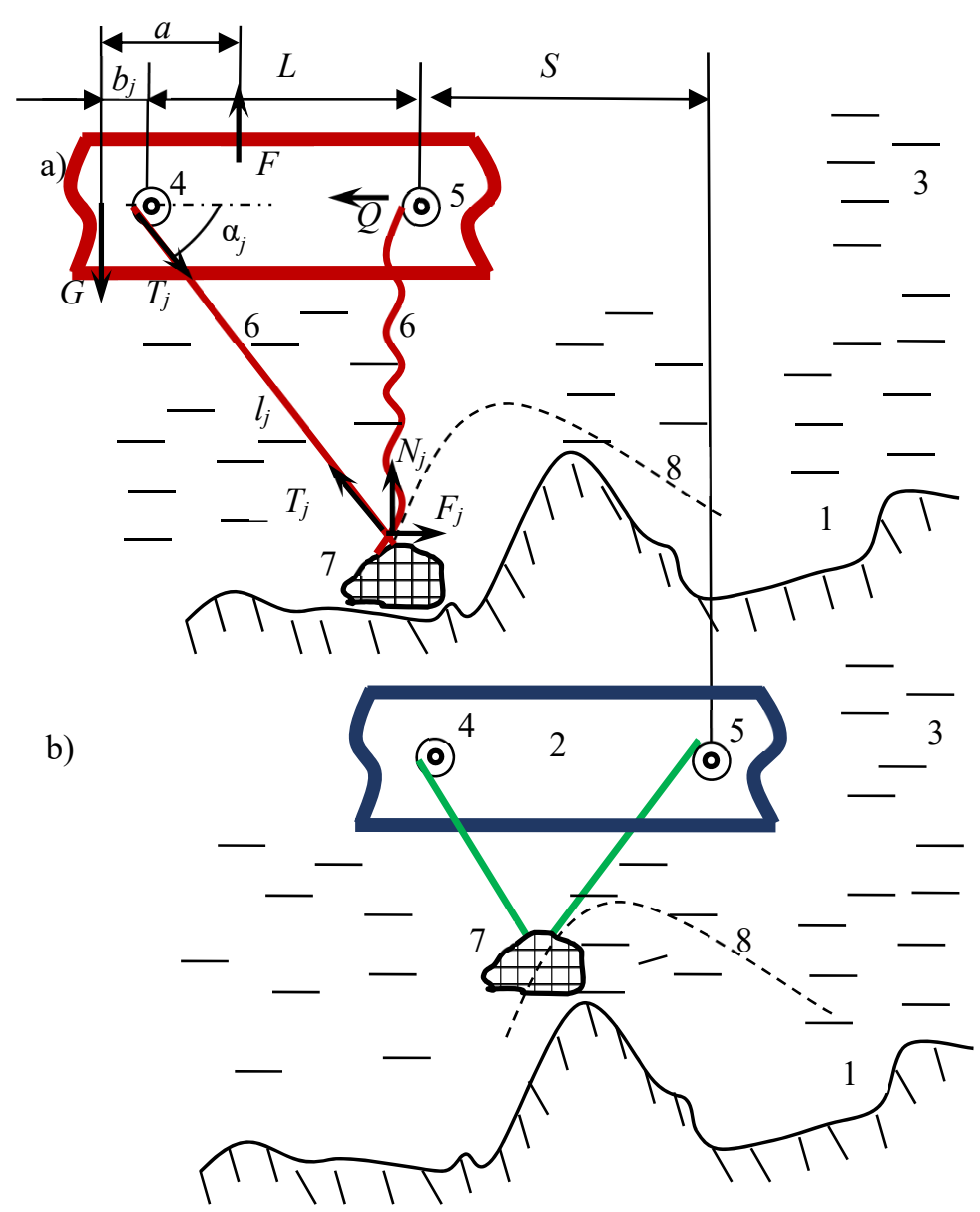

1 - bottom surface, 2 - fragment of a robot pontoon, 3 - water medium, 4, 5 - cable length control drives, 6 - cables, 7 anchor, 8 - anchor transfer path

Figure 1. The principle of operation and calculation scheme of the anchor-cable propulsion device: a) translational horizontal movement of the fragment of the robot pontoon by distance $L$ due to pulling the drive 4 ; b) The movement of the platform at a distance $S$ due to other propulsors and the transfer of the anchor to a new position due to the coordinated operation of drives 4 and 5 .

The work of such a propulsion device is similar to the work of a walking [6], but the difference is that the robot does not rest on the mover, but is held by it relative to the supporting surface and, being pulled to the anchor, moves in the horizontal direction.

The advantages of such propulsion devices over the bottom-supported ones (wheeled, tracked, walking) is in almost ideal profile passability, and over propulsion devices based on water repulsion (screw, water-jet, etc.) in greater energy efficiency, more accurate positioning of the platform body and its stability, provided for the most part by control of the tension forces of the cables and their location, and not by the position of the loads on the platform. 
A more efficient energy transfer is due to the fact that it is carried out due to the interaction of the mover with the soil, and not with the aquatic environment. Indeed, in order for a body of mass $m$ to move at a speed $V$, another body of mass $M$ must acquire a speed $U$, but directed in the opposite direction:

$$
U=\frac{m}{M} V
$$

For this, it is necessary do work A:

$$
A=\frac{1}{2} m V^{2}+\frac{1}{2} M U^{2}=\frac{1}{2} m V^{2}\left(1+\frac{m}{M}\right) .
$$

In the case of a propulsion devices contact with the soil without slippage in equations $(1,2)$, $M$ is the mass of the Earth, in the case of propeller, oar, or fish-tail motion [19] $M$ is the mass of discarded water. Therefore, from the point of view of energy efficiency and equipment positioning, it is better to interact with the ground, and from the point of view of cross-country ability and ease of control, it is better to swim.

A feature of mobile robots moving in an aqueous environment is the presence of buoyancy force, which can be commensurate with the weight of the robot.

Therefore, a reasonable compromise is the use of mobile robots floating at a low height from the bottom, and the use of anchor-cable propulsion devices interacting with the bottom of the reservoir as means of movement (Figure 1).

The main problems in calculating such propulsion devices and determining the optimal modes of their movement are:

- determination of the number of anchor-cable propulsion devices, their mass and installation location at the robot-pontoon;

- minimization of the roll and trim of the pontoon when changing the position of the center of mass of the transported cargo within the specified limits;

- substantiation of energy effective modes of translational movement of the robot pontoon. The solution of the tasks set, based on the study of translational uniform steady motion of the platform (Figure 1), can be written as

$$
\sum_{j=1}^{N} T_{j} \cos \alpha_{j}-Q=0, \quad-\sum_{j=1}^{N} T_{j} \sin \alpha_{j}+F-G=0, \quad-\sum_{j=1}^{N} T_{j} b_{j} \sin \alpha_{j}+F a=0 .
$$

where $\mathrm{a}$ is the distance from the center of mass of the robot to the point of application of the buoyant force $F, b_{j}$ is the distance from the center of mass of the robot to the axis of the drum, $\alpha_{j}$ is the angle of orientation of the cable, $G$ is the weight of the body of the robot applied to the center of mass of the body, $T_{j}$ is the force in the cable, holding the $j$-th anchor, $j=1 \ldots N, N$ is the number of anchors. Sagging cables are not taken into account due to their short length.

When the robot body is moved and the anchors are in the same position, the angles $\alpha_{j}$ and the cable lengths $l_{j}$ change depending on the path $S$

$$
\operatorname{tg} \alpha_{j}=\frac{l_{j 0} \sin \alpha_{j 0}}{l_{j 0} \cos \alpha_{j 0}-S}, \quad l_{j}=\sqrt{\left(l_{j 0} \cos \alpha_{j 0}-S\right)^{2}+l_{j 0}^{2} \sin ^{2} \alpha_{j 0}} .
$$

where $\alpha_{j 0}, l_{j 0}$ are the initial values of the angles and lengths of the cables.

The equilibrium equations of resting anchors are of the form 


$$
\left\{\begin{array}{l}
N_{j}+T_{j} \sin \alpha_{j}-m g=0 \\
F_{j}-N_{j} \cos \alpha_{j}=0
\end{array},\right.
$$

where $N_{j}, m g, F_{j}$ respectively the normal reaction, the weight of the anchor and the strength of adhesion to the ground.

The condition for the feasibility of translational steady motion of the platform (3) is the fulfillment of the inequalities

$$
\begin{aligned}
& N_{j}=m g-T_{j} \sin \alpha_{j}>0 \\
& F_{\max } \geq\left(m g-T_{j} \sin \alpha_{j}\right) \cos \alpha_{j}
\end{aligned}
$$

Equations (3) are supplemented by $N-3$ control equations in the problem under consideration with the excessive presence of unsteady connections [20] (anchor-cable propulsion devices)

$$
\sum_{j=1}^{N} A_{j i} T_{j}=B_{i}, i=1,2 \ldots N-3
$$

where $A_{j i}, B_{i}$ are, respectively, the elements of the matrix $A$ and the control vector $B$ [8], selected on the basis of criteria, for example, the equality of all the tension forces, or their minimum, or the minimum of heat losses in drive motors controlling the length of the cables, etc. Fulfillment (7) is ensured by the laws of control of drives of anchor-cable propulsion devices [21].

Thus, the goal of the control is to provide the tension force of the cables $T_{j}$ of the propulsion devices, both interacting with the ground and transferred to a new position. For propulsion devices interacting with soil

$$
0<T_{j}<m g-f
$$

where $f$ is the buoyant force acting on the anchor.

The lower boundary in (8) is due to the case of a complete sagging of the cable, and the upper one due to the separation from the ground.

The propulsion device can be moved to a new position along different paths, in accordance with various laws depending on the surface profile [22]. The basis for the choice of transfer laws is the criterion of the minimum heat loss $A$ in engines [23] in the form

$$
A=\alpha \sum \int_{0}^{\tau} T_{j}^{2} \mathrm{~d} t,
$$

where $\tau$ is the transfer time of the foot; $\alpha$ is a known characteristic of drive motors; $T_{j}$ is the force developed by $j$ drives.

It is possible to require a minimum rms power $W$ developed by the engines [24] in the form of criterion $I$, defined by the expression

$$
I=\frac{1}{\tau} \int_{0}^{\tau} W^{2} \mathrm{~d} t=\frac{1}{\tau} \int_{0}^{\tau}[m \dot{V}+F]^{2} \mathrm{~d} t,
$$

where $V$ is the speed of the robot, $F$ is the force of resistance to movement.

Criteria $(9,10)$ should be the basis for choosing the parameter $b_{j}$ for the placement of anchor-cable propulsion devices, the mass of $m$ anchors and the relationship between the forces in the cables of the propulsion devices, characterized by $A_{j i}, B_{i}$ matrices in control equations (7). 


\section{The principle of operation of robots of vertical movement and the problems of calculating their modes of motion}

Vertical movement robots with cable drives (Figure 3) in addition to the main drive 1, whose operation provides a change in the length of the cable, , has a drive 2 that controls the position of the additional mass $\xi(t)$ of the robot, as well as braking drives 3 of free wheel. Additional drives are necessary for reliable contact of the robot 4 with a vertical surface and when overcoming obstacles on the surface due to overstepping. The stages of the algorithm of the movement of the robot on a vertical surface are schematically presented in Figure 4.

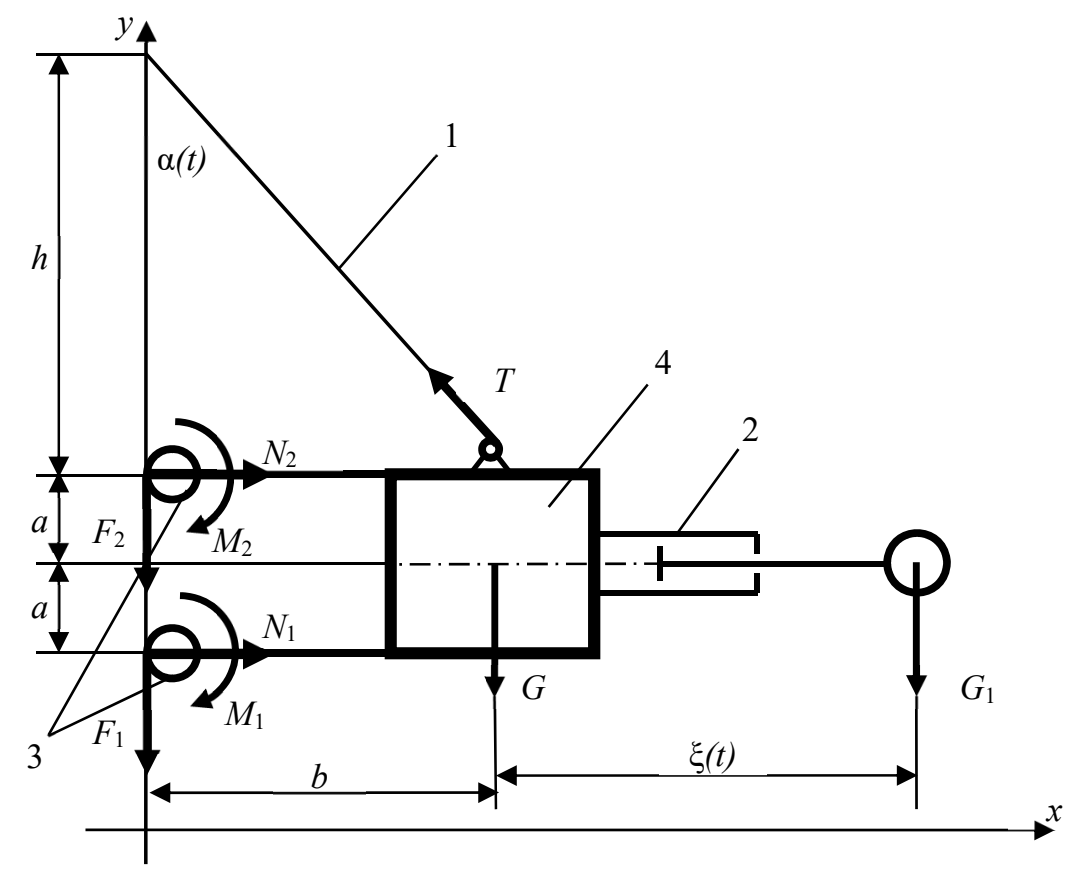

Figure 3. The design scheme of the robot vertical movement:

1 - cable drive 2 - drive of control position of additional mass position, 3 - wheel with a brake, 4 - robot.

When moving the robot along a vertical surface (Figure 4), with a small constant velocity of the center of mass, the equations of motion have the form

$$
\left\{\begin{array}{l}
N_{1}+N_{2}-T \sin \alpha(t)=0 \\
-F_{1}-F_{2}-G-G_{1}+T \cos \alpha(t)=0 \\
-G b-G_{1}[b+\xi(t)]-N_{2} 2 a+2 a T \sin \alpha(t)+b T \cos \alpha(t)-M_{1}-M_{2}=0
\end{array}\right.
$$

where $N_{1}, N_{2}$ are normal reactions with a vertical surface at the points of contact of wheels, $F_{1} \leq f N_{1}, F_{2} \leq f N_{2}$ are tangent reactions (Coulomb friction forces with a coefficient of friction $f$ ) at points of contact of wheels with a vertical surface, $M_{1}=\delta N_{1}, M_{2}=\delta N_{2}$ - the moments of friction of rolling the wheels, $G, G_{1}$ - the weight of the robot and the additional load, $a, b, h . \alpha$-geometric parameters of the design scheme (Figure 4). 


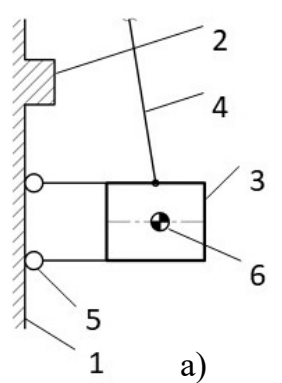

a)

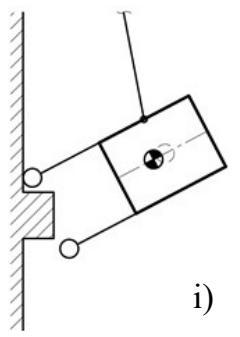

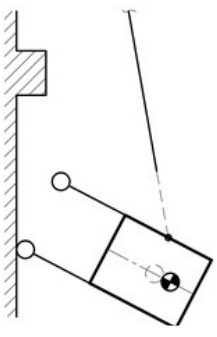

b)

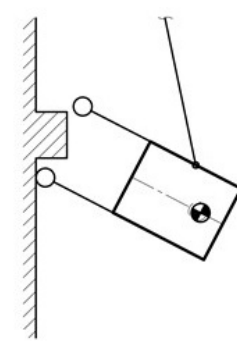

c)

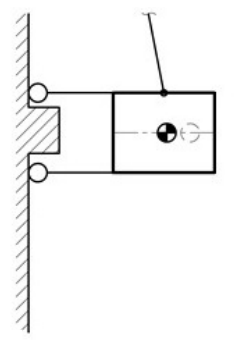

d)
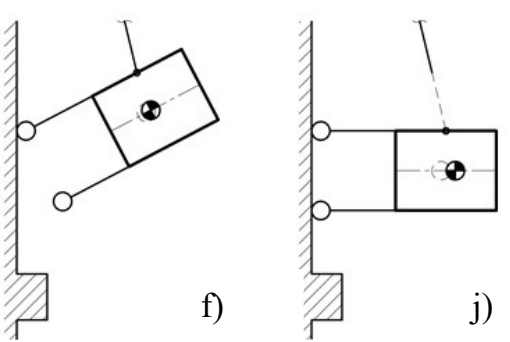

Figure 4. The movement of the robot vertical movement. 1 - vertical surface, 2 - obstacle, 3 - body, 4 - cable, 5 wheel with a brake; 6 - controlled load.

The initial cable length $l_{0}$ and its extension $\Delta l$ are related to the angle $\alpha$ of the cable tilt to the vertical surface

$$
\sin \alpha(t)=\frac{b}{l_{0}-\Delta l(t)} .
$$

If we neglect the forces of friction, then equations (8) are enough to determine $N_{1}, N_{2}, T$ :

$$
\left\{\begin{array}{l}
T=\frac{G+G_{1}}{\cos \alpha(t)} \\
N_{1}=\frac{\delta\left(G+G_{1}\right) \operatorname{tg} \alpha(t)+G_{1} \xi(t)}{2 a} \\
N_{2}=\frac{(2 a-\delta)\left(G+G_{1}\right) \operatorname{tg} \alpha(t)-G_{1} \xi(t)}{2 a}
\end{array}\right.
$$

Then the main task is to determine the law of change in the position of the corrective load with a weight of $G_{1}$, providing the required indicators of the quality of movement:

- maximum squared normal reactions

$$
I_{N}=N_{1}^{2}+N_{2}^{2}
$$

- minimum heat loss in the drive of the cable mover

$$
I_{W}=\int_{0}^{\tau} T^{2} d t
$$

for a given vertical movement of the robot $\Delta y$ both on a flat vertical surface, and when overcoming discrete obstacles. 


\section{Conclusions}

The cable mover is promising for use in mobile robots.

The main task of calculating cable propulsion devices is the task of placing them on the robot and determining the optimal modes of movement.

\section{Acknowledgments}

The work was supported by the Russian Science Foundation (grant No. 18-71-10069).

\section{References}

1. E.I. Yurevich, Fundamentals of Robotics, St. Petersburg, BHV-Petersburg, (2005). (In Russ.).

2. B.B. Mikhailov, A.V. Nazarova, A.S. Yushchenko, Avtonomnye mobil'nye roboty navigatsiya i upravlenie - Izvestiya YuFU. Tekhnicheskie nauki, 2 (175), 48-67 (2016). (In Russ.).

3. I.A. Kalyaev, A decentralized system for planning and controlling the activity of a team of mobile robots - Cybernetics, 21 (4), pp. 533-538, (1985).

4. D. Okhotsimsky, A. Platonov, A. Kiril'chenko, V. Lapshin, V. Tolstousova, Walking machines - Advances in Mechanics, vol. 15, no. 1-2, 39-70 (1992).

5. F.L. Chernousko, Analysis and optimization of the motion of a body controlled by means of a movable internal mass - Journal of Applied Mathematics and Mechanics, vol. 70, no. 6, 819-842 (2006).

6. E.S. Briskin, etc., Dinamika i upravlenie dvizheniem shagajushhih mashin s ciklovymi dvizhiteljami (Dynamics and motion control of walking machines with cyclic movers). Mashinostroenie (2009) (in Russian).

7. V.G. Gradetskiy, M.Yu. Rachkov, Yu.G. Sizov, S.V. Ul'yanov, F.L. Chernous'ko, Mobile systems with vertical displacement robots - Journal of Computer and Systems Sciences International, 31 (1), 126-142 (1993).

8. N.V. Bykov, N.S. Vlasova, M.Y. Gubanov, D.V. Lapin, A Locomotion Mechanism for a Mobile Wall-Climbing Robot with a Hybrid Magnetic-Tape Adhesion Method. Mekhatronika, Avtomatizatsiya, Upravlenie, 21(3) 158-165 (2020). (In Russ.)

9. N. Elkmann, T. Felsch, M. Sack, J. Saenz, J. Hortig, Innovative service robot systems for facade cleaning of difficult-to-access areas - In Proc. of the 2002 IEEE/RSJ International Conference on Intelligent Robotsand Systems, 1, 756-762 (2002).

10. M. Silva, J. Machado, J. Tar, A survey of technologies for climbing robots adhesion to surfaces - Proc. of the 6th IEEE Conference on Computational Cybernetics, 127-32 (2008).

11. Yu.F. Golubev, V.V. Koryanov, A control for an insectomorphic robot in motion along a vertical corner and a horizontal beam - Journal of Computer and Systems Sciences International, vol. 45, no. 1, 144-152 (2006).

12. R. Parker, K. Bayne, P. Clinton, Robotics in forestry - New Zealand Journal of Forestry, 60(4), 8-14 (2016).

13. E.S. Briskin, N.G. Sharonov, V.S. Barsov, On Energy Efficient Regimes of Robot Motion with Rotary-Wedging Propulsion Devices, Mekhatronika, Avtomatizatsiya, Upravlenie, 19(2), 100-103 (2018). (In Russ.).

14. A.V. Maloletov, M.Y. Fadeev, A.S. Klimchik, Error Analysis in Solving the Inverse Problem of the Cable-driven Parallel Underactuated Robot Kinematics and Methods for their Elimination - IFAC-PapersOnLine, 52 (13), 1156-1161 (2019).

15. V.N. Platonov, E.S. Briskin, N.G. Sharonov, On the features of the progressive movement of the solid body, controlled by two propulsion devices - IOP Conference Series: Materials Science and Engineering, 489 (1), 012058 (2019). 
16. E.S. Briskin, N.G. Sharonov, V.A. Serov, I.S. Penshin, Motion control of underwater mobile robot with anchor-rope propulsion devices - Robotics and Technical Cybernetics, 2(19), 39-45 (2018).

17. E.S Briskin, V.V. Gulevsky, I.S. Penshin, N.G. Sharonov, About features of management of mobile robots with stepping movers of a rope type in a water environment - IOP Conf. Ser.: Mater. Sci. Eng. 747012080 (2020).

18. M.I. Efimov, E.S Briskin, N.G. Sharonov, On the movement of the rope robot on a vertical surface- IOP Conf. Ser.: Mater. Sci. Eng. 747012082 (2020).

19. S. Jatsun, B. Lushnikov, E. Politov, S. Knyazev, Underwater floating robot-fish: A comparative analysis of the results of mathematical modelling and full-scale tests of the prototype - MATEC Web of Conferences, 113, 02014 (2017).

20. E.S. Briskin, N.G. Sharonov, On Motion Control of Mechanical Systems with an Excessive Number of Control Actions - Journal of Computer and Systems Sciences International, 58 (3), 374-381 (2019).

21. E.S. Briskin, V.N. Platonov, On Math Modeling of Solid Body's Motion Control with an Excess Number of Rope Propulsion Devices. Mekhatronika, Avtomatizatsiya, Upravlenie, 20(7), 422-427 (2019). (In Russ.)

22. E.S. Briskin, Y.V. Kalinin, A.V. Maloletov, V.A. Serov, S.A. Ustinov, On controlling the adaptation of orthogonal walking movers to the supporting surface - Journal of Computer and Systems Sciences International, 56 (3),519-526 (2017).

23. E.S. Briskin, Y.V. Kalinin, A.V. Maloletov, Estimates of efficiency of cycle mechanisms Mechanics of Solids, 52 (2), 128-133(2017).

24. D.V. Bordugov, E.S. Briskin, Y.V. Kalinin, Determination of the program mode of mobile robot progressive motion with the minimum power motor - Proceedings of International Conference of Young Scientists and Students «Topical Problems of Mechanical Engineering 2019», 445-448 (2020). (In Russ.). 